\title{
PRE AND POST IRON THERAPY ABSOLUTE RETICULOCYTE COUNT- A RELIABLE TEST WITH EARLY RESPONSE TO TREATMENT IN IRON DEFICIENCY ANAEMIA
}

\author{
A. P. Jonathan Arnold ${ }^{1}$, Dhamini Durairaj2
}

${ }_{1}^{1}$ Associate Professor, Department of Pathology, Sri Venkateshwaraa Medical College Hospital and Research Centre, Pondicherry, India. ${ }^{2}$ Final Year MBBS Student, Dhanalakshmi Srinivasan Medical College and Hospital, Perambalur, Tamilnadu, India.

\section{ABSTRACT}

\section{BACKGROUND}

Iron deficiency anaemia is usually treated using oral iron therapy as first line treatment. Several tests are available to monitor the response to oral iron treatment, but absolute reticulocyte count [ARC] is supposed to be the one showing one of the quickest responses, with an increase of ARC within 5 to 10 days of therapy initiation. Our aim is to verify that ARC is significantly increased following iron therapy and that the response is quick and cost effective.

\section{METHODS}

50 adults with recently diagnosed but untreated iron deficiency anaemia were included in this prospective cohort study. Haemoglobin [Hb], RBC indices, peripheral smear and ARC were done at baseline [T0], day 7 [T1] and day 30 [T2] after the start of oral iron therapy.

\section{RESULTS}

Mean (SD) Hb level at T0 was 8.93 (1.41) g/dl [Hb0]. It increased to 9.22 (1.33) g/dl [Hb1] and 10.59 (1.28) g/dl [Hb2] at T1 and T2, respectively. Mean (SD) ARC level at T0 was $19.6 \times 10^{9}\left(12.7 \times 10^{9}\right) / 1$ [ARC0]. It increased to $80.15 \times 10^{9}\left(28.1 \times 10^{9}\right) / 1$ [ARC1] at $\mathrm{T} 1$ and then reduced to $36.08 \times 10^{9}\left(17.9 \times 10^{9}\right) / 1$ [ARC2] at T2. Using Repeated measures ANOVA, there was a statistically significant $(\mathrm{p}<0.0001)$ increase in mean $\mathrm{Hb} 2$ compared to mean $\mathrm{Hb} 0$ (baseline), while there was no significant rise of mean $\mathrm{Hb} 1$ when compared with mean Hb0. 84\% showed at least $1 \mathrm{~g} / \mathrm{dL}$ increase of Hb by day 30. Mean ARC1 was statistically higher $(p<0.001)$ than mean ARC0, while mean ARC2 was significantly lower ( $p$ value $<0.001$ ) than mean ARC1. Based on Spearman correlation test, there was a positive correlation ( $r=0.282, n=50, p<0.05$ - significant) between relative rise of Hb [after 30 days] and relative rise of ARC [after 7 days].

\section{CONCLUSIONS}

Our study confirms that ARC is an ideal early predictor of response to iron therapy as it increases by $7^{\text {th }}$ day compared with $\mathrm{Hb}$ which does not rise significantly till 4 weeks of therapy. Also, ARC can be done manually, requiring no special equipment and therefore cost effective especially in resource constrained settings.

HOW TO CITE THIS ARTICLE: Arnold APJ, Durairaj D. Pre and post iron therapy absolute reticulocyte count- a reliable test with early response to treatment in iron deficiency anaemia. J. Evolution Med. Dent. Sci. 2019;8(20):1662-1666, DOI: $10.14260 /$ jemds/2019/367

\section{BACKGROUND}

Iron deficiency is probably the most common cause of anaemia on the planet, affecting at least one-third of the world's population.(1) Iron deficiency anaemia [IDA] is associated with weakness, fatigue, difficulty concentrating and reduced physical activity, which lead to impairment in quality of life and work productivity.(2-4) In elderly people, even low levels of anaemia affect the quality of life and increase the risk of mortality resulting in many medical conditions such as cardio-vascular and cognitive disorders, osteopenia, muscle weakness, falls and fractures, and depression.(5) Studies have shown that IDA correlates with decreased cognitive performance and poor work productivity.(6-8) Hence, early detection and treatment of anaemia is mandatory.

'Financial or Other Competing Interest': None.

Submission 01-04-2019, Peer Review 04-05-2019,

Acceptance 11-05-2019, Published 20-05-2019.

Corresponding Author:

Dr. A. P. Jonathan Arnold,

Department of Pathology,

Sri Venkateshwaraa Medical College Hospital and Research Centre,

Pondicherry, No. 13A, Pondy-Villupuram Main Road, Ariyur-605102,

Pondicherry, Tamilnadu, India.

E-mail: jonathanarnold79@gmail.com

DOI: $10.14260 /$ jemds $/ 2019 / 367$
Iron deficiency anaemia can be suspected by reduction in the following laboratory indicators: Haemoglobin [Hb], Haematocrit [PCV], RBC count, Mean Corpuscular Volume[MCV], Mean Corpuscular Haemoglobin [MCH], Mean Corpuscular Haemoglobin Concentration [MCHC] along with a raised Red cell Distribution Width [RDW]. Peripheral smear findings include microcytes, hypochromic RBC \& anisopoikilocytosis.(9) Oral iron replacement is the most economical and preferred medication for the treatment of iron deficiency anaemia. Yet, failure of oral iron therapy may occur in case of i) Inadequate prescription ii) Continuing iron loss in excess of intake iii) Malabsorption of iron iv) Associated illness such as anaemia of inflammation in rheumatoid arthritis, Helicobacter pylori infection and Celiac disease.(10) Failure of treatment may also occur in case of incorrect diagnosis of other conditions like Thalassemia, Sideroblastic anaemia, myelodysplastic syndromes as Iron deficiency anaemia.(11) Since the routine laboratory tests are not sufficient to distinguish these conditions, they may go unnoticed until the ineffective response to treatment is found. So, we need other sensitive \&more specific indicators in detecting IDA which include reduction in serum iron, serum ferritin, transferrin saturation [TS] and increase in Total Iron Binding Capacity [TIBC] \& soluble transferrin receptor levels. But, these tests are relatively costly and lab facilities necessary for performing these tests are not available among 
all health care centres. Perl's iron staining of bone marrow smears is a sensitive marker of body iron stores but not a first line of investigation since it is invasive.

Response to treatment can be identified by both clinical and laboratory investigations. Clinically, tongue and nails are the most responsive to treatment. In tongue, filiform papillae regenerate after 1 to 2 weeks and tongue returns to normal after 3 months. In nails, koilonychia takes 3 to 6 months to disappear.(10) Lab investigations useful in monitoring response include $\mathrm{RBC}$ count, $\mathrm{Hb}$ level, RDW, Red cell indices, Reticulocyte count, serum ferritin, TIBC and TS. Haematocrit reaches half way towards normal by 3 weeks and Haemoglobin reaches normal levels by 2 months after therapy is initiated.(10,12) Red cell indices may remain abnormal for some time even after the normal Haemoglobin level is restored. A study conducted among hospitalized patients revealed that MCV has low sensitivity whereas TIBC and TS have low specificity in detecting IDA.(13)

Of all, the earliest haematological evidence of response to treatment is an increase in the percentage of reticulocytes. Reticulocytes are juvenile red blood cells containing reticular network of rRNA. Once the bone marrow starts responding to treatment, an increase in reticulocyte count is expected. Reticulocyte count can be recorded either as a percentage [Normal count is about $0.5 \%$ to $2.5 \%$ in adults(9)] or as an absolute reticulocyte count [normal range in adults: $50-100 \mathrm{x}$ $\left.10^{9} / \mathrm{L}^{(9)}\right]$. The reticulocytes attain a maximal value on $5^{\text {th }}$ to $10^{\text {th }}$ day after initiation of therapy.(10) The maximal value usually ranges from $5 \%$ to $10 \%$. No special technology is required for this procedure which makes it more preferable. To verify the reliability of this test, a prospective cohort study was planned to be conducted among the newly diagnosed cases of iron deficiency anaemia reporting in a tertiary health care centre. Previous study conducted in same regard among paediatric age group confirms the effectiveness of ARC in predicting the response to iron therapy.(14) This study was planned to assess whether pre and post iron therapy absolute reticulocyte count is a reliable\& early method to monitor response to iron therapy in adults.

The primary objective of this study was to find whether ARC was a reliable laboratory indicator for predicting response to oral iron in iron deficiency anaemia patients. This was achieved by determining whether there was a significant increase in absolute reticulocyte count after initiation of iron therapy and whether the increase in absolute reticulocyte count was early and cost effective.

\section{METHODS}

After getting clearance from the Institutional Ethics Committee (IEC), Prospective cohort study was conducted among the newly diagnosed cases of iron deficiency anaemia (diagnosis was based on reduced Haemoglobin [Adult male: < $13 \mathrm{~g} / \mathrm{dL}$; Adult female: $<12 \mathrm{~g} / \mathrm{dL}$, raised RDW and peripheral smear findings of microcytic hypochromic RBCs) reporting in a Tertiary Health Care Centre in Perambalur district. 50 adults irrespective of gender were selected by simple random sampling method from the cohort of patients with proven iron deficiency anaemia. Sample size was taken based on the convenience of the study. After obtaining informed written consent, all adult patients with laboratory evidence of iron deficiency anaemia who required oral iron therapy were included in the study. All patients in whom iron therapy had already been started, in whom treatment other than oral iron therapy was required, who were lost to follow up, paediatric patients $(<12$ years age) and patients unwilling for the study were excluded.

Data collected included demographic details and baseline laboratory investigations comprising of Haemoglobin, Haematocrit, RBC count, MCV, MCH, MCHC, RDW [all tests done using Horiba 5-part haematology analyser], peripheral blood smear findings and ARC. One week and one month after start of iron therapy, blood sample was collected and Haemoglobin, Haematocrit, RBC count, MCV, MCH, MCHC (CBC) and ARC investigations were carried out. The same pathologist (to avoid individual variation) reported all the reticulocyte counts and he was blinded of the study. Reticulocyte count [both \% and ARC] was done using standard procedure routinely done in the tertiary care centre in which two to three drops of commercially available reticulocyte staining fluid (New methylene blue) was taken in a $75 \times 10 \mathrm{~mm}$ plastic tube by means of a plastic Pasteur pipette. To this 2-4 volumes of the patient's EDTA anticoagulated blood was added and incubated at $37^{\circ} \mathrm{C}$ for 20 minutes. The mixture was gently mixed, and films were made on glass slides and examined under the microscope. Reticulocytes were identified as red cells with blue precipitate, granules or filaments in the cytoplasm. Reticulocyte count is given by the formula:

Reticulocyte count [\%] = Number of reticulocytes in "n" fields x 100 $(9)$

[Number of fields ("n") x Average number of red cells per field]

ARC $=$ Reticulocyte count $[\%] \times$ RBC count $/ \mathrm{L}^{(10)}$

For severe anaemia the reticulocyte count was corrected \{corrected ARC = Reticulocyte count [\%] $\mathrm{x}$ (Patient Haematocrit/45)\}.(10) Samples [from normal healthy volunteers without anaemia] were used as quality control for ARC.

\section{Statistical Methods}

Data were entered in Excel and statistical analysis done using SPSS 20.0 software. A p value of $<0.05$ was considered as statistically significant. The ARC before iron therapy, 1 week and 1 month after iron therapy were compared using repeated measures ANOVA test and its significance determined. Similarly, the Haemoglobin level before iron therapy, 1 week and 1 month after iron therapy were also compared by the same statistical test.

The correlation between ARC and Haemoglobin levels was done by Spearman correlation test. The response to iron treatment was evaluated by improvement in haematology parameters [> $1 \mathrm{~g} / \mathrm{dL}$ increase of Haemoglobin,(15) Haematocrit, RBC count, MCV, MCH, MCHC] one month after start of therapy.

\section{RESULTS}

Fifty patients of proven iron deficiency anaemia, predominantly female patients, had a mean (SD [Standard Deviation]) age of 36.18 yrs. (13.87), and ranging from 20 to 80 years. The three blood samples from study participants were labelled as T0 [before initiation of iron therapy], T1 [1 week after iron therapy] and T2 [1 month after iron therapy] respectively, the corresponding Haemoglobin values were designated as $\mathrm{Hb} 0, \mathrm{Hb} 1$ and $\mathrm{Hb} 2$, and $\mathrm{ARC}$ as ARC1, ARC2 and ARC3. 

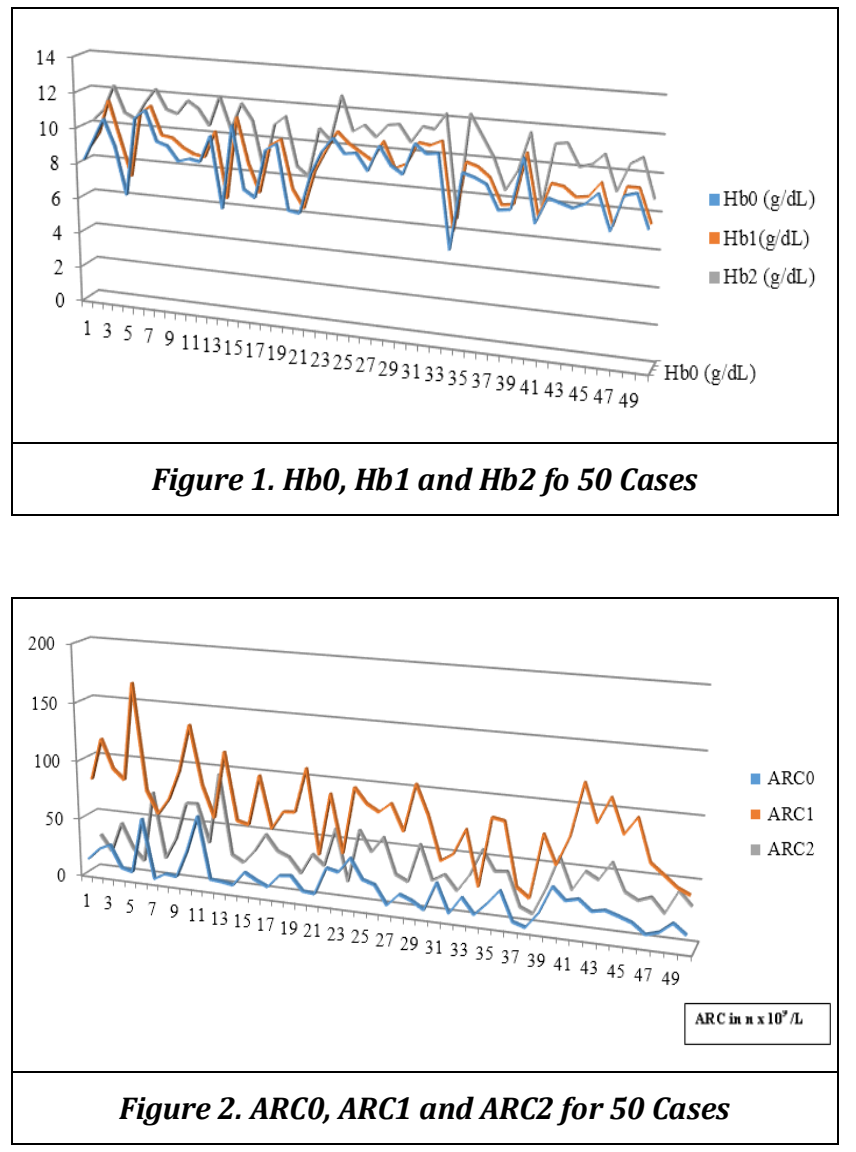

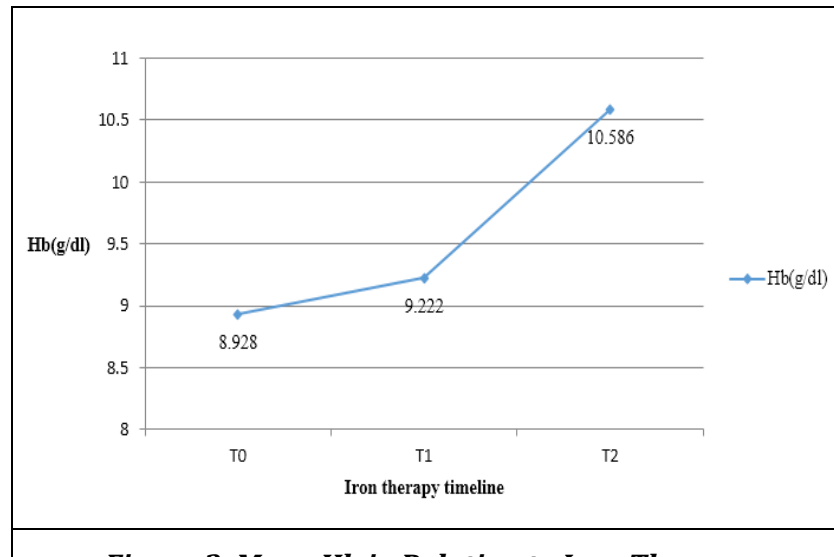

Figure 3. Mean Hb in Relation to Iron Therapy

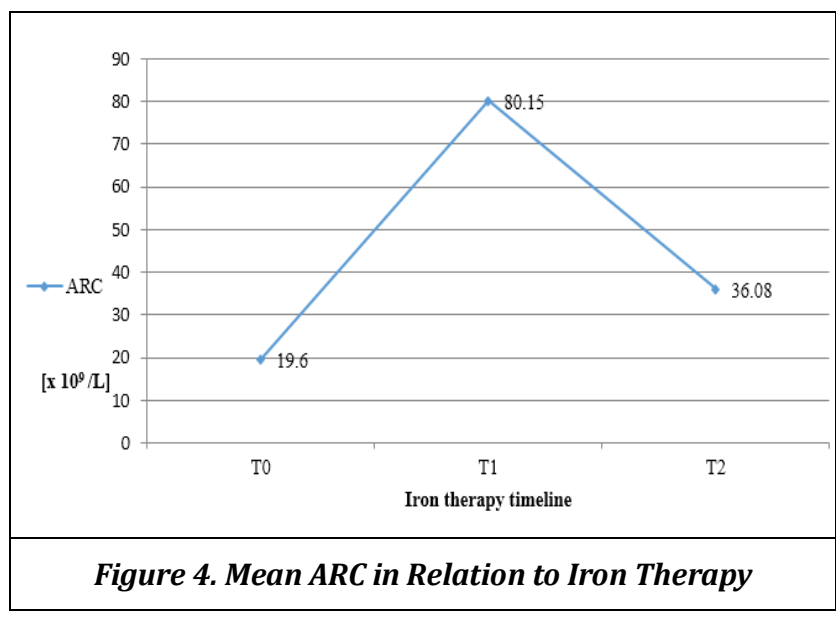

\begin{tabular}{|c|c|c|c|c|c|c|c|c|c|}
\hline $\begin{array}{c}\text { Lab } \\
\text { parameter }\end{array}$ & \begin{tabular}{|c|} 
Mean(SD) for \\
blood \\
sample T0
\end{tabular} & $\begin{array}{c}\text { Mean(SD) } \\
\text { for blood } \\
\text { sample T1 }\end{array}$ & $\begin{array}{l}\text { Mean(SD) } \\
\text { for blood } \\
\text { sample T2 }\end{array}$ & $\begin{array}{c}\text { †Mean } \\
\text { diff } \\
\text { T1-T0 }\end{array}$ & $\begin{array}{c}\text { Mean } \\
\text { diff } \\
\text { T2-T1 }\end{array}$ & $\begin{array}{c}\text { Mean } \\
\text { diff } \\
\text { T2-T0 }\end{array}$ & $\begin{array}{l}\text { p value } \\
\text { TOvsT1 }\end{array}$ & $\begin{array}{l}\text { p value } \\
\text { T1vsT2 }\end{array}$ & $\begin{array}{c}\text { p value } \\
\text { T0vsT } \\
2\end{array}$ \\
\hline $\mathrm{Hb}(\mathrm{g} / \mathrm{dL})$ & \begin{tabular}{|l|}
$8.928(1.41)$ \\
\end{tabular} & $9.222(1.33)$ & $10.586(1.28)$ & 0.29 & 1.36 & 1.66 & $<0.01$ & $<0.001$ & $<0.001$ \\
\hline ARC(x109)/L & $19.6(12.7)$ & $80.15(28.1)$ & $36.08(17.9)$ & 60.55 & -44.07 & 16.48 & $<0.001$ & $<0.001$ & $<0.001$ \\
\hline $\begin{array}{c}\text { RBC(million/ } \\
\mathrm{mm}^{3} \text { ) }\end{array}$ & $3.614(0.48)$ & $3.832(0.41)$ & $4.574(0.44)$ & 0.22 & 0.74 & 0.96 & $<0.001$ & $<0.001$ & $<0.001$ \\
\hline PCV \% & $27.82(3.70)$ & $29.2(3.58)$ & $32.32(2.86)$ & 1.38 & 3.12 & 4.50 & $<0.01$ & $<0.001$ & $<0.001$ \\
\hline MCV(fL) & 69.28(9.13) & $73.00(8.85)$ & 77.68(7.33) & 3.72 & 4.68 & 8.40 & $<0.001$ & $<0.001$ & $<0.001$ \\
\hline MCH(pg) & $22.34(3.85)$ & $23.64(3.71)$ & $26.88(3.94)$ & 1.30 & 3.24 & 4.54 & $<0.01$ & $<0.001$ & $<0.001$ \\
\hline MCHC(g/dL) & $31.50(1.81)$ & $31.92(1.51)$ & $32.94(1.49)$ & 0.42 & 1.02 & 1.44 & $<0.05$ & $<0.001$ & $<0.001$ \\
\hline \multicolumn{10}{|c|}{ Table-1. Mean Lab parameters for the three blood samples } \\
\hline
\end{tabular}

$\mathrm{Hb}$ and ARC for all the three samples are presented in figures 1 and 2 respectively which show $\mathrm{Hb} 0$ values ranging from $5.30 \mathrm{~g} / \mathrm{dL}$ to $10.90 \mathrm{~g} / \mathrm{dL}, \mathrm{Hb} 1$ values ranging from 6.1 $\mathrm{g} / \mathrm{dL}$ to $11.5 \mathrm{~g} / \mathrm{dL}, \mathrm{Hb} 2$ values ranging from $6.6 \mathrm{~g} / \mathrm{dL}$ to 12.7 $\mathrm{g} / \mathrm{dL}, \mathrm{ARC} 0$ values ranged from $3.6 \mathrm{x} 10^{9} / \mathrm{L}$ to $63 \mathrm{x} 10^{9} / \mathrm{L}$, ARC1 values ranging from $23.8 \times 10^{9} / \mathrm{L}$ to $168 \times 10^{9} / \mathrm{L}$, and ARC2 values ranging from $7.2 \times 10^{9} / \mathrm{L}$ to $94.3 \times 10^{9} / \mathrm{L}$. Mean (SD) $\mathrm{Hb0}$ was 8.93(1.41) g/dL, Hb1 was 9.22(1.33)g/dL and $\mathrm{Hb} 2$ was $10.59(1.28) \mathrm{g} / \mathrm{dL}$ (fig.3). Mean (SD) ARC0 was $19.6 \mathrm{x}$ $10^{9}\left(12.7 \times 10^{9}\right) / \mathrm{L}, \mathrm{ARC} 1$ was $80.15 \times 10^{9}\left(28.1 \times 10^{9}\right) / \mathrm{L}$ and ARC2 was $36.08 \times 10^{9}\left(17.9 \times 10^{9}\right) /$ L (Fig. 4 ).
Since both Haemoglobin and ARC follow normal distribution, Repeated measures ANOVA was applied to compare the means. Data analysis using repeated measures ANOVA comparing the different RBC parameters and their significance are given in Table 1.

\section{DISCUSSION}

$\mathrm{Hb} 2$ was significantly higher compared to $\mathrm{Hb} 0$ and $\mathrm{Hb} 1 \mathrm{Cp}<$ 0.001) whereas the rise of $\mathrm{Hb}$ from $\mathrm{Hb} 0$ to $\mathrm{Hb} 1$ was not that significant $(p<0.01)$ whereas there was a statistically significant $(\mathrm{p}<0.001)$ increase in ARC from ARC0 to ARC1 and a decrease in ARC values by $30^{\text {th }}$ day (ARC2). 82\% [41 cases] showed an increase of $1 \mathrm{~g} / \mathrm{dL}$ Haemoglobin by $30^{\text {th }}$ day 
after iron therapy i.e., $82 \%$ responded to treatment with oral iron (15). Relative rise of $\mathrm{Hb}(\mathrm{Hb} 2-\mathrm{Hb} 0 / \mathrm{Hb} 0)$ after a month and relative rise of ARC (ARC1-ARC0/ARC0) after a week were compared using Spearman correlation test to identify the correlation between rise of $\mathrm{Hb}$ and ARC. The analysis showed that there was a positive correlation between relative rise of $\mathrm{Hb}$ after a month and relative rise of ARC after a week ( $\mathrm{r}=0.282, \mathrm{n}=50, \mathrm{p}<0.05$ - significant $)$.

Okam et al(16) in their analysis of 738 cases had a mean $\mathrm{Hb}$ of $9.3 \mathrm{~g} / \mathrm{dL}$ while in our study the baseline $\mathrm{Hb}$ was 8.93 $\mathrm{g} / \mathrm{dL}$ which was almost similar. $72.8 \%$ cases had an increase of $\mathrm{Hb}$ of $>1 \mathrm{~g} / \mathrm{dL}$ after 14 days of iron therapy, whereas in our study $82 \%$ of cases had an increase of $\mathrm{Hb}$ of $>1 \mathrm{~g} / \mathrm{dL}$ after 30 days of treatment. Okam et al found that the rise of ARC had an $81.9 \%$ positive predictive value in predicting a rise of $>2$ $\mathrm{g} / \mathrm{dL} \mathrm{Hb}$ at day $42-56$ interval. In our study, in $82 \%$ of cases the rise in ARC1 (Day $7 \mathrm{ARC}$ ) accurately predicted a $\mathrm{Hb} 2$ (day $30 \mathrm{Hb}$ ) increase of at least $1 \mathrm{~g} / \mathrm{dL}$, while in $18 \%$ cases the ARC increase was not associated with a concomitant increase of $\mathrm{Hb}$. This requires further evaluation.

Parodi et al(14) did a study on 34 cases of children with IDA measuring both $\mathrm{Hb}$ and ARC at baseline, 7 days \& 30 days after oral iron therapy. In their study, mean (SD) Hb level before treatment (T0) was 6.84

(1.22) g/dL which increased to $7.36 \mathrm{~g} / \mathrm{L}$ (1.31) and 10.56 $\mathrm{g} / \mathrm{L}$ (1.62) at $\mathrm{T} 1$ and $\mathrm{T} 2$ respectively, while the $\mathrm{Hb}$ parameters in our study were 8.93(1.41) g/dL, 9.22(1.33) $\mathrm{g} / \mathrm{dL}$ and $10.59(1.28) \mathrm{g} / \mathrm{dL}$ at T0, T1 and T2, respectively. Mean (SD) ARC in the Parodi et al study was $72.8 \times 10^{9} / \mathrm{L}$ (35.155) before treatment (T0). It increased to $168.6 \times 10^{9} / \mathrm{L}$ (101.2) at T1 and then decreased again to $76.3 \times 10^{9} / \mathrm{L}$ (38.9) at T2, respectively. In our study Mean (SD) ARC level at T0 was $19.6 \times 10^{9} / \mathrm{L}\left(12.7 \times 10^{9}\right)$. It increased to $80.15 \times 10^{9} / \mathrm{L}$ $\left(28.1 \times 10^{9}\right)$ at $\mathrm{T} 1$ and then reduced to $36.08 \times 10^{9} / \mathrm{L}(17.9 \times$ $10^{9}$ ) at T2. On comparing both studies, we found that both had a significant increase of mean ARC by $7^{\text {th }}$ day after iron therapy. We deduce from our study as well as the studies by Parodi et al and Okam et al that ARC rises very early around 7 days after initiation of iron therapy. These findings support the theory that ARC is an early indicator of response to iron treatment.

Parodi et al's statistics show that though in $5 \%$ of cases the rise of $\mathrm{Hb}$ was $<1 \mathrm{~g} / \mathrm{dL}, 30$ days after iron therapy, there was an increase of ARC on day 7 on all those cases. Similarly, in our study in $18 \%$ cases, $\mathrm{Hb}$ rose $<1 \mathrm{~g} / \mathrm{dL}$ after 30 days and all of them also had a rise of ARC at 7 th day. This finding requires further evaluation of the reason for non-rise of $\mathrm{Hb}$ even though ARC increased.

A population study done to monitor response to iron intervention revealed that serum ferritin is more consistent in predicting response. This study included 9 randomized control trials in which serum ferritin increased in all trials and was significant in 7 of them.(17) However, several studies revealed that serum iron, TIBC, ferritin and transferrin are acute phase reactants that can be elevated depending on the presence of co-existing infectious or inflammatory conditions.(18-20) Transferrin saturation may also be decreased in the anaemia of chronic inflammation. A case controlled study conducted in Amirkola town among elderly ( $>60$ yrs.) people with coexisting morbidities revealed that IDA can develop even with normal or higher Serum Ferritin.(21) Therefore, even though serum ferritin can consistently predict the response to iron therapy, it may not be valid in the presence of underlying inflammation, whereas ARC is not affected by the same. Van Santen et al(22) conducted a study to predict response to oral iron therapy in patients with chronic inflammation. They concluded that in patients with chronic inflammation, an increase in Haemoglobin level of at least $0.81 \mathrm{~g} / \mathrm{dL}$ at week 6 of iron therapy were best predicted by an increase of Ret-He $(\mathrm{Hb}$ content of reticulocytes), transferrin saturation, serum iron level and the reticulocyte count one week after iron therapy. Base-line values of ferritin, hepcidin, sTfR-index (Soluble transferrin receptor) and RBC-He (Hb content of $\mathrm{RBC}$ ) also predicted the hematopoietic response, but to a lesser degree, according to their study.

Brugnara et al(23) conducted a study among 10 iron deficient adult females which showed that mean (SD) ARC increased significantly from 65.15 (29.3) X $10^{9} / \mathrm{L}$ to 130.45 (60.0) X $10^{9} / \mathrm{L}$ after 1 or 2 weeks after oral iron replacement therapy $(\mathrm{p}<0.001$, paired t-test). In our study, mean(SD) ARC increased from 19.6 (12.7) X 109/L to 80.15 (28.1) X 109/L after 1 week of iron therapy which shows that there was a similar rise in ARC between both studies even though the baseline mean values of ARC were different. In this study, Flow cytometric analysis of 0xazine 750-stained reticulocytes was done with the help of Miles $\mathrm{H}^{*} 3$ blood analyser to determine reticulocyte indices. In our study, manual routinely used lab procedure was used. This further raises a question about the difference in ARC values in different experimental setup which needs further evaluation by larger studies. This study also found that other indices were not much significant in predicting response to iron replacement therapy, but ARC was positive well in advance of the traditional increase of at least $1 \mathrm{~g} / \mathrm{dL}$ of Haemoglobin after 1 month of iron treatment.

\section{CONCLUSIONS}

Firstly, our study confirms the fact that oral iron improves haemoglobin level as we noted that $82 \%$ of our cases improved by at least $1 \mathrm{~g} / \mathrm{dL}$ in 30 days. Secondly, within one week of therapy there is no significant increase of $\mathrm{Hb}$ compared to baseline values whereas absolute reticulocyte count increased significantly in the same period. Hence this conclusively proves that ARC is an early indicator of response to oral iron therapy. Thirdly, as is already known, the cost of ARC is very less compared to other tests for monitoring the response to iron therapy like serum ferritin, transferrin saturation, total iron binding capacity and bone marrow evaluation. Therefore, ARC is a cost-effective alternative to monitor iron therapy response.

Since our study was of a short duration, we limited our study to 50 cases, and we could not identify cases in which there was no increase of ARC. More studies on larger cohorts is required to identify cases which do not have an increase of ARC so that we could confirm if lack of ARC increase corresponds to failure of response to iron treatment. Also, some cases $(16 \%)$ in which there was no $\mathrm{Hb}$ response however showed an ARC increase. This requires further study on maturation of reticulocytes to RBCs to understand the reasons behind this finding. Further studies are required to analyse the differences between manual and automated methods of reticulocyte counts. 


\section{ACKNOWLEGEMENTS}

We thank Dhanalakshmi Srinivasan Medical College Hospital for the space and lab services for conducting the research and ICMR for the student stipend.

\section{REFERENCES}

[1] McPherson RA, Pincus MR. Henry's clinical diagnosis and management by laboratory methods. 21st edn. Philadelphia: Elsevier Health Sciences 2016.

[2] Camaschella C. Iron-deficiency anaemia. N Engl J Med 2015;372(19):1832-1843.

[3] Haas JD, Brownlie T. Iron deficiency and reduced work capacity: a critical review of the research to determine a causal relationship. J Nutr 2001;131(2S-2):676S688S.

[4] Patterson AJ, Brown WJ, Powers JR, et al. Iron deficiency, general health and fatigue: results from the Australian Longitudinal Study on Women's Health. Qual Life Res 2000;9(5):491-7.

[5] Busti F, Campostrini N, Martinelli N, et al. Iron deficiency in the elderly population, revisited in the hepcidin era. Front Pharmacol 2014;5:83.

[6] Sachdev H, Gera T, Nestel P. Effect of iron supplementation on mental and motor development in children: systematic review of randomised controlled trials. Public Health Nutr 2005;8(2):117-32.

[7] Glazer Y, Bilenko N. Effect of iron deficiency and iron deficiency anaemia in the first two years of life on cognitive and mental development during childhood. Harefuah 2010;149(5):309-14.

[8] Haas JD, Fairchild MW. Summary and conclusions of the international conference on iron deficiency and behavioral development, October 10-12, 1988. Am J Clin Nutr 1989;50(3):703-5.

[9] Bain BJ, Bates I, Laffan MA. Dacie and Lewis practical haematology. 10 $10^{\text {th }}$ edn. London: Elsevier Health Sciences 2016.

[10] Nancy CA. Iron deficiency and related disorders In: Greer JP, Foerster J, Rodgers GM, et al, eds. Wintrobe's clinical hematology. $12^{\text {th }}$ edn. Philadelphia. Lippincott Williams \& Wilkins 2009.

[11] Kasper D, Longo DL, Fauci AS, et al. Harrison's Principles of internal medicine. 19th edn. New York: McGraw-Hill 2015.

[12] McPhee SJ, Papadakis MA, Tierney LM. Current medical diagnosis \& treatment. New York: McGrawHill Medical 2016.
[13] Burns ER, Goldberg SN, Lawrence C, et al. Clinical utility of serum tests for iron deficiency in hospitalized patients. Am J Clin Pathol 1990;93(2):240-5.

[14] Parodi E, Giraudo MT, Ricceri F, et al. Absolute reticulocyte count and reticulocyte Haemoglobin content as predictors of early response to exclusive oral iron in children with iron deficiency anaemia. Anaemia 2016;2016:1-6.

[15] Short MW, Domagalski JE. Iron deficiency anaemia: evaluation and management. Am Fam Physician 2013;87(2):98-104.

[16] Okam MM, Koch TA, Tran MH. Iron supplementation, response in iron-deficiency anaemia: analysis of five trials. Am J Med 2017;130(8):991.e1-8.

[17] Mei Z, Cogswell ME, Parvanta I, et al. Haemoglobin and ferritin are currently the most efficient indicators of population response to iron interventions: an analysis of nine randomized controlled trials. J Nutr 2005;135(8):1974-80.

[18] Ozdemir N. Iron deficiency anaemia from diagnosis to treatment in children. Turk Pediatri Ars 2015;50(1):11-9.

[19] Ratcliffe LE, Thomas W, Glen J, et al. Diagnosis and Management of Iron Deficiency in CKD: a summary of the NICE Guideline Recommendations and Their Rationale. Am J Kidney Dis 2016;67(4):548-58.

[20] Thurnham DI, McCabe LD, Haldar S, et al. Adjusting plasma ferritin concentrations to remove the effects of subclinical inflammation in the assessment of iron deficiency: a meta-analysis. Am J Clin Nutr 2010;92(3):546-55.

[21] Babaei M, Shafiei S, Bijani A, et al. Ability of serum ferritin to diagnose iron deficiency anaemia in an elderly cohort. Rev Bras Hematol Hemoter 2017;39(3):223-8.

[22] van Santen S, de Mast Q, Oosting JD, et al. Hematologic parameters predicting a response to oral iron therapy in chronic inflammation. Haematologica 2014;99(9):e171-3.

[23] Brugnara C, Laufer MR, Friedman AJ, et al. Reticulocyte Haemoglobin content (CHr): early indicator of iron deficiency and response to therapy. Blood 1994;83(10):3100-1. 